\title{
Association among oral symptoms, oral health-related quality of life, and health- related quality of life in a sample of adults living with HIV/AIDS in Malaysia
}

\author{
Nurulasmak Mohamed ${ }^{1}$, Norkhafizah Saddki ${ }^{1 *}$ (D, Azizah Yusoff $^{1}$ and Anilawati Mat Jelani²
}

\begin{abstract}
Background: Health-related quality of life (HRQOL) is a multidimensional construct that refers to an individual's selfperceived well-being. This study used the revised Wilson and Cleary HRQOL model to investigate the associations among oral symptoms, oral health-related quality of life (OHRQOL), and HRQOL of people living with HIV/AIDS (PLWHA) in Malaysia.

Methods: A total of 121 PLWHA receiving medical care in Kota Bharu (Kelantan, Malaysia) participated in this cross-sectional study. The Malay version of the short Oral Health Impact Profile (S-OHIP(M)) and the Malay version of the 36-item Medical Outcome Study Short Form (SF-36) were used to assess OHRQOL and HRQOL, respectively. A higher S-OHIP(M) score indicates greater oral impact and worse OHRQOL; a higher SF-36 score indicates better HRQOL. An additional structured self-administered questionnaire was used to obtain other variables of interest from the participants.

Results: Most participants had at least one oral symptom (69.4\%), and the most common oral symptom was a cavitated tooth (55.4\%). The prevalence of oral impacts was 33.9\%, and the mean S-OHIP(M) score was 8.8 (SD = 7.92). The mean S-OHIP(M) score was significantly higher in participants who had toothaches, cavitated teeth, gum abscesses, and bad breath. In addition, participants with lower S-OHIP(M) scores had significantly higher scores in all SF-36 domains.

Conclusions: Our study provides evidence for an association among oral symptoms, OHRQOL, and HRQOL in PLWHA from Malaysia. In particular, the presence of oral symptoms was significantly associated with more severe oral impacts and poorer OHRQOL. The presence of less severe oral impacts was associated with a better HRQOL.
\end{abstract}

Keywords: HIV, Quality of life, Oral health, Malaysia

\section{Background}

HIV infection remains one of the world's major public health issues. The use of highly active antiretroviral therapy (HAART) has reduced global AIDS-related deaths from 1.5 million in 2010 to 1.1 million in 2015 [1]. Additionally, sustained viral suppression and subsequent reduction of viral load in the blood and other bodily fluids has led to substantial decreases in the incidence of AIDS-defining events and AIDS-related morbidity, and has also reduced

\footnotetext{
* Correspondence: fizah@usm.my

${ }^{1}$ School of Dental Sciences, Universiti Sains Malaysia, Health Campus, 16150

Kubang Kerian, Kelantan, Malaysia

Full list of author information is available at the end of the article
}

the number of new HIV infections because of the lower likelihood of HIV transmission per exposure event [2-5]. However, the number of new HIV infections being reported each year is still high, and the improved survival time means there is a persistent increase in the number of people living with chronic HIV infections [6]. Approximately 36.7 million people worldwide had HIV infections in 2015, compared to 33.3 million in 2010 [1]. Similarly, in Malaysia, there has been a steady decline in the annual number of new HIV cases and AIDS-related deaths since 2002 [7]. In 2014, Malaysia had an estimated 86,324 people living with HIV/AIDS (PLWHA) [7]. 
In tandem with the increased life expectancy of PLWHA, assessment of health-related quality of life (HRQOL) has become an important part of patient management [8]. The term HRQOL refers to an individual's self-perceived well-being at any given period that contributes to satisfaction and happiness in life [9]. The HRQOL is a multidimensional construct, and previous studies have conceptualized it in a variety of ways. The most frequently used HRQOL model is based on work by Wilson and Cleary [10]. The Wilson and Cleary model is a causal model that links 5 levels of health outcomes: biological and physiological variables, symptom status, functional status, general health self-perceptions, and overall quality of life [11]. Individual and environmental characteristics influence the symptom status, functional status, general health self-perceptions, and overall quality of life; non-medical factors also have an influence on the overall quality of life [11].

The Wilson and Cleary model was revised in 2005 by Ferrans et al. [12]. In particular, they redefined the influence of individual and environmental characteristics on the health outcomes by adding a link between these factors to biological function (originally "biological and physiological variables"), but maintained the other characteristics. Ferrans et al. also removed unnecessary intermediary linkages, as well as the non-medical domain, because all non-medical factors can be categorized as either individual or environmental [12]. The revision resulted in a simpler and clearer depiction of health outcomes and related factors. A recent systematic review of HRQOL models recommended the revised Ferrans et al. model [12] because it better explains HRQOL than the original Wilson and Cleary model [10].

Previous studies have identified factors associated with the HRQOL of PLWHA. These include age, sex, ethnicity, education level, marital status, employment, social support, duration of living with the infection, CD4+ cell count, HAART treatment status, presence of HIVrelated symptoms, co-morbidities, and psychological symptoms [13-18]. Previous HIV/AIDS studies have used various HRQOL instruments, but no instrument is optimal and no single instrument is accepted as the 'gold standard' [19]. Furthermore, most instruments used to assess HRQOL in clinical studies of PLWHA do not include indicators of oral health, although it is welldocumented that oral mucosal lesions and oral health problems, such as dental caries and periodontal disease, are common in PLWHA [19-24].

Oral diseases may cause symptoms such as pain, discomfort, altered taste, and a burning sensation. Additionally, oral symptoms may interfere with the chewing of food, pronunciation of certain words and sounds, and smiling and socializing with confidence. The Oral Health Impact Profile (OHIP), developed by Slade and Spencer
[25], is one of the most widely used instruments to assess the impact of oral diseases on life experiences or oral health-related quality of life (OHRQOL). This instrument is based on the conceptual model for measuring oral health proposed by Locker [26]. Although many studies have assessed the determinants of HRQOL in PLWHA, only few have reported the relationship between OHRQOL and HRQOL.

The purpose of this study was to investigate the association among oral symptoms, OHRQOL, and HRQOL of HIV-infected individuals receiving medical care in Kota Bharu (Kelantan, Malaysia). We used the revised Wilson and Cleary model of HRQOL by Ferrans et al. [12] to examine the relationships of measured health outcomes with their determinants.

\section{Methods}

\section{Population and sample}

This cross-sectional study was conducted from April to May of 2013. The source population comprised of HIVinfected individuals receiving medical care at Hospital Raja Perempuan Zainab II (HRPZ II), Kota Bharu, Kelantan. HRPZ II is a tertiary referral centre for the management of HIV for people living in Kelantan and neighbouring states, particularly Terengganu and Pahang. The Infectious Disease Clinic, under the purview of the Department of Medicine, provides medical care for HIVinfected individuals. Clinical sessions are held twice weekly, and about 20 individuals are seen during each session.

The inclusion criteria were aged 18 years and above, has been living with HIV for at least 1 year, and was able to write and read in the Malay language. The sample size needed to adequately address the study objective was calculated for a power of $80 \%$ and significance level of 0.05 . Thus, a sample size of 123 was needed. The ethical approval to conduct this study was obtained from the Universiti Sains Malaysia Human Research and Ethics Committee and the Ministry of Health Malaysia Medical Research and Ethics Committee.

\section{Research tools}

The Malay version of short Oral Health Impact Profile (S-OHIP(M)) was used to measure the impact of oral problems on OHRQOL [27]. This questionnaire has 2 items in each of the following 7 domains: functional limitation, physical pain, psychological discomfort, physical disability, psychological disability, social disability, and handicap. A 5-point Likert scale was used to assess the frequency of oral impacts during the previous 12 months, and coded as '0' for 'never,' ' 1 ' for 'hardly ever', '2' for 'occasionally', '3' for 'fairly often' and '4' for 'very often'. The total score of all 14 items (range: 0 to 56) was calculated to determine the overall severity of the impact, as a reflection of functional status. A higher S-OHIP(M) 
score indicates greater oral impact, and a poorer OHRQOL. The prevalence of impact which was the percentage of participants who reported 'fairly often' or 'very often' to one or more items was also determined.

The HRQOL of the participants was measured using the Malay version of the 36-item Medical Outcome Study Short Form (SF-36) [28]. This tool covers 8 health domains, assessed by 35 items: 10 physical functioning items (limitations in physical activities because of health problems), 4 role-physical items (limitations caused by physical health problems), 2 bodily pain items, 5 general health items, 4 vitality items (energy and fatigue), 3 roleemotional items (limitations caused by emotional problems), 2 social functioning items (limitations in social activities because of physical or emotional problems), and 5 mental health items (psychological distress and well-being). An additional item asks about self-perceived current general health status compared to the previous year, which we used to represent the general health perceptions component described in the revised Wilson and Cleary model of HRQOL. Items in the role-physical and role-emotional domains use 'yes/no' answers and other items are scored on 3- to 6-point Likert scales. For each domain, the coded and re-coded item scores were summed and transformed according to the standard SF36 scoring algorithm [29]. The transformed domain scores are reported on a scale of 0 (worst possible health state) to 100 (best possible health state).

Additionally, a structured self-administered questionnaire (Additional file 1) was developed to determine individual characteristics (age, sex, ethnic group, education level, marital status, employment status, monthly income, and duration of HIV infection), environmental characteristics (HAART status and duration), biological function (CD4+ T-lymphocyte count and presence of co-infection), and oral symptoms (toothache, cavitated tooth, gum pain, gum swelling, gum bleeding, gum abscess, loose tooth, bad breath, and mouth ulcer). The content validity of the questionnaire was determined by an expert panel, and a pre-test was given to 30 PLWHA who were receiving care at the Infectious Disease Clinic, Hospital Raja Perempuan Zainab II, Kota Bharu, Kelantan. Participants' written informed consent was obtained. Figure 1 shows the conceptual framework of variables examined in this study.

\section{Data collection}

A systematic random sampling method was used to identify potential participants from the patient appointment list. The main researcher approached potential participants while they were waiting to be seen by physicians, and invited them to participate in this study. Written informed consent was obtained from each participant prior to enrolment. All questionnaires were self-administered and anonymous. Completed questionnaires were immediately collected.

\section{Statistical analysis}

Data entry and analysis of the results were performed using IBM SPSS for Windows (version 22). All data were first examined and cleaned to prevent errors. Descriptive statistics of all variables were determined; mean and standard deviation (SD) for continuous variables and frequency and percentage for categorical variables. An analysis of variance (ANOVA) was used to compare the mean S-OHIP(M) scores of participants with different general health perceptions. A one sample $t$-test was used to compare the mean SF-36 health domain scores with those of the Malaysian general population, reported previously [30].

The association of S-OHIP(M) score with oral symptoms and with overall quality of life (mean SF-36 health domain score) were determined by univariable and multivariable

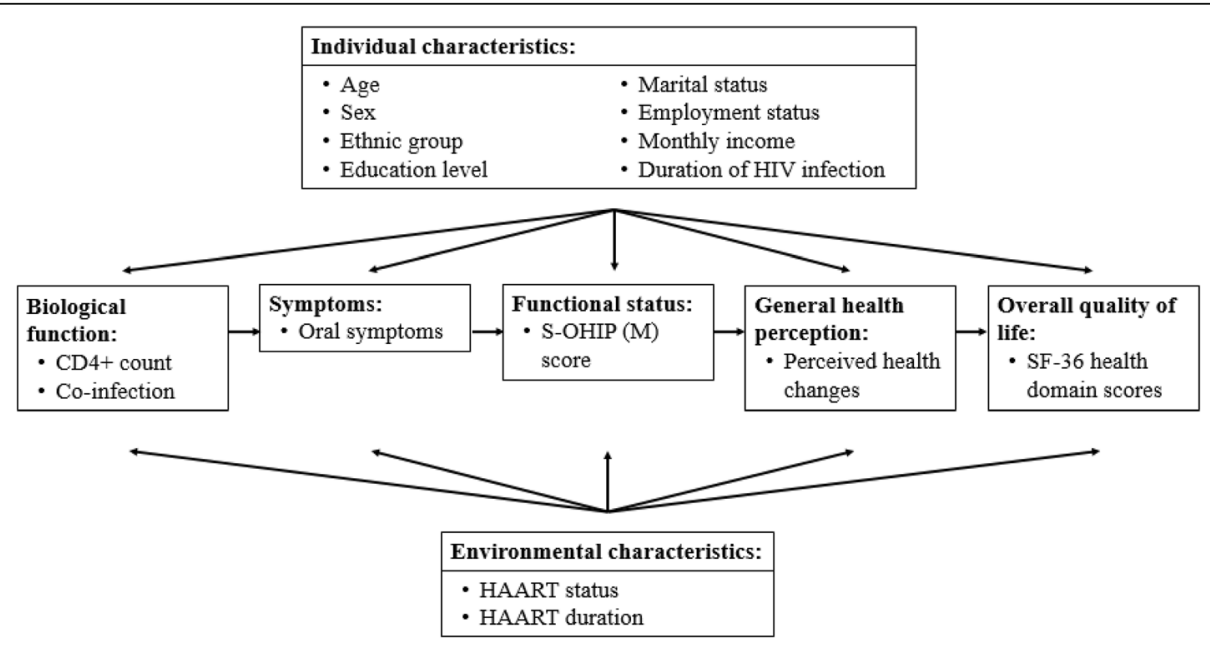

Fig. 1 Conceptual framework of variables examined in this study, based on the revised Wilson and Cleary model by Ferrans et al. [12] 
analysis using simple linear regression and general linear regression analysis, respectively. The multivariable analysis of the association between oral symptoms and S-OHIP(M) score controlled for age, sex, ethnic group, education level, marital status, employment status, monthly income, duration of HIV infection, CD4+ T-lymphocytes count, HAART status and duration, and presence of co-infection. The multivariable analysis of the association between SOHIP(M) score and SF-36 health domain mean scores controlled for age, sex, ethnic group, education level, marital status, employment status, monthly income, duration of HIV infection, CD4+ T-lymphocytes count, HAART status and duration, presence of co-infection, oral symptoms, and general health perceptions. Variable selection was done using three methods: stepwise selection, backward selection, and forward selection. Following variable selection, all possible two-way interactions, multicollinearity problems, model assumptions, and outliers were checked.

\section{Results}

A total of 123 PLWHA initially enrolled, but 2 patients (1.6\%) were dropped, leaving 121 study participants. The 2 excluded patients gave very similar and dubious answers for all S-OHIP(M) items. Table 1 summarises the characteristics of the 121 study participants. The age range was 18 to 57 years-old and the mean age was 38.9 years-old $(\mathrm{SD}=6.42)$. The participants have lived with HIV for an average of 7.4 years $(\mathrm{SD}=4.23)$. The median personal monthly income was 700 Malaysian Ringgit (MYR) (inter-quartile range $[\mathrm{IQR}]=925$ ).

Table 2 shows the self-perceived oral health status of the participants. Most participants had at least one oral symptom (69.4\%), and the most common oral symptom was a cavitated tooth (55.4\%).

The prevalence of oral impacts was $33.9 \%$, and the mean S-OHIP(M) score was 8.8 (SD = 7.92). Table 3 shows the mean S-OHIP(M) score for each S-OHIP(M) domain and item, and the proportion of participants reporting impact for each item. The most affected oral health domain was psychological discomfort, which had a mean score of $2.1(\mathrm{SD}=1.95)$. An item within the psychological discomfort domain - discomfort due to food getting stuck between teeth or dentures - had the highest mean score and prevalence. The lowest oral impact was for social disability, and no participant reported having impacts of 'fairly often' or 'very often' for "avoided going out".

Table 4 shows the results of multivariable analysis of the association between oral symptoms and S-OHIP(M) score. The S-OHIP(M) score was significantly and positively associated with oral symptoms, particularly toothache, cavitated tooth, gum abscess, and bad breath. Personal monthly income was significantly and negatively associated with S-OHIP(M) score. Overall, the
Table 1 Characteristics of study participants

\begin{tabular}{|c|c|}
\hline Variable & Frequency (\%) \\
\hline \multicolumn{2}{|l|}{ Age group (years) } \\
\hline$\leq 30$ & $9(7.4)$ \\
\hline $31-40$ & $68(56.2)$ \\
\hline $41-50$ & $37(30.6)$ \\
\hline$>50$ & $7(5.8)$ \\
\hline \multicolumn{2}{|l|}{ Sex } \\
\hline Female & $50(41.3)$ \\
\hline Male & $71(58.7)$ \\
\hline \multicolumn{2}{|l|}{ Ethnic group } \\
\hline Malay & $111(91.7)$ \\
\hline Others & $10(8.3)$ \\
\hline \multicolumn{2}{|l|}{ Highest education level } \\
\hline Primary school & $15(12.4)$ \\
\hline Secondary school & $94(77.7)$ \\
\hline Certificate/diploma & $9(7.4)$ \\
\hline Degree & $3(2.5)$ \\
\hline \multicolumn{2}{|l|}{ Marital status } \\
\hline Never been married & $31(25.6)$ \\
\hline Married & $58(47.9)$ \\
\hline Divorced/widowed & $32(26.4)$ \\
\hline \multicolumn{2}{|l|}{ Employment status } \\
\hline Regular jobs & $76(62.8)$ \\
\hline Odd jobs & $18(14.9)$ \\
\hline Unemployed & $27(22.3)$ \\
\hline \multicolumn{2}{|l|}{ Personal monthly income (MYR) } \\
\hline$\leq 500$ & $56(46.3)$ \\
\hline $501-1000$ & $43(35.5)$ \\
\hline $1001-1500$ & $13(7.4)$ \\
\hline$>1500$ & $9(7.4)$ \\
\hline \multicolumn{2}{|l|}{ Duration of HIV infection (years) } \\
\hline $1-5$ & $46(38.0)$ \\
\hline $6-10$ & $53(43.8)$ \\
\hline$>10$ & $22(18.2)$ \\
\hline \multicolumn{2}{|l|}{ Route of exposure to HIV } \\
\hline Injecting drug & $36(29.8)$ \\
\hline Sexual contact & $69(57.0)$ \\
\hline Injecting drug and sexual contact & $15(12.4)$ \\
\hline Others & $1(0.8)$ \\
\hline \multicolumn{2}{|l|}{ CD4+ T-lymphocytes count (cells/mm³) } \\
\hline$\leq 199$ & $21(17.4)$ \\
\hline $200-499$ & $65(53.7)$ \\
\hline$\geq 500$ & $35(28.9)$ \\
\hline \multicolumn{2}{|l|}{ HAART treatment status } \\
\hline No & $23(19.0)$ \\
\hline Yes & $98(81.0)$ \\
\hline \multicolumn{2}{|l|}{ Co-infection } \\
\hline Hepatitis C & $27(22.3)$ \\
\hline Tuberculosis & $15(12.4)$ \\
\hline
\end{tabular}


Table 2 Self-perceived oral health status of study participants

\begin{tabular}{ll}
\hline Variable & Frequency (\%) \\
\hline Perceived oral health status & $6(5.0)$ \\
Very good & $59(48.8)$ \\
Good & $37(30.6)$ \\
Fair & $16(13.2)$ \\
Poor & $3(2.5)$ \\
Very poor & \\
Number of oral symptoms & $37(30.6)$ \\
None & $30(24.8)$ \\
One problem & $54(44.6)$ \\
Two or more & \\
Oral symptoms & $33(27.3)$ \\
Toothache & $67(55.4)$ \\
Cavitated tooth & $14(11.6)$ \\
Gum pain & $23(19.0)$ \\
Gum swelling & $22(18.2)$ \\
Gum bleeding & $5(4.1)$ \\
Gum abscess & $25(20.7)$ \\
Loose tooth & $19(15.7)$ \\
Bad breath & $9(7.4)$ \\
Mouth ulcer &
\end{tabular}

model explains $43.1 \%$ of the variation in the S-OHIP(M) score $\left(R^{2}=0.431\right)$.

Descriptive analysis of general health perceptions, as measured by changes in perceived general health status in the past year, indicated that most participants thought they were either somewhat better (40.5\%) or much better $(22.3 \%)$ at the time of the study. However, some participants felt either about the same $(28.1 \%)$ or somewhat worse $(8.3 \%)$, and a small number felt much worse $(0.8 \%)$. An ANOVA that compared the mean S-OHIP(M) scores of participants with different general health perceptions indicated a significant difference (Table 5). A subsequent post-hoc test, using Tukey's HSD procedure, showed that the mean S-OHIP(M) score of participants who thought they were much worse or somewhat worse was significantly different from the score of participants who thought they were about the same.

Table 6 compares the mean SF-36 domain scores of PLWHA in this study (all participants and participants on HAART) with those of the general Malaysian population reported previously [30]. These results show that our study population has a significantly higher score in the bodily pain domain, and significantly lower scores in the physical functioning domain, role-physical domain, general health domain, social functioning domain, and mental health domains. There were no significant differences in the vitality and role-emotional domains. The
Table 3 Prevalence and severity of oral impact (S-OHIP(M) score) in study participants

\begin{tabular}{lll}
\hline S-OHIP(M) domain and item & $\begin{array}{l}\text { Prevalence of } \\
\text { impact (\%) }\end{array}$ & $\begin{array}{l}\text { Mean S-OHIP } \\
\text { (M) score (SD) }\end{array}$ \\
\hline Functional limitation & - & $1.7(1.84)$ \\
Difficulty chewing any foods & 13.2 & $1.1(1.19)$ \\
Problems caused bad breath & 5.0 & $0.6(0.94)$ \\
Physical Pain & - & $1.3(1.53)$ \\
Discomfort eating any food & 9.9 & $0.8(1.08)$ \\
Ulcers in mouth & 4.1 & $0.5(0.83)$ \\
Psychological Discomfort & - & $2.1(1.95)$ \\
Discomfort due to food getting stuck & 19.8 & $1.4(1.23)$ \\
Felt shy & 9.1 & $0.7(1.04)$ \\
Physical disability & - & $1.5(1.75)$ \\
Avoided eating certain foods & 9.9 & $0.9(1.11)$ \\
Avoided smiling & 7.4 & $0.6(0.99)$ \\
Psychological Disability & - & $0.9(1.48)$ \\
Sleep been disturbed & 1.7 & $0.4(0.75)$ \\
Concentration been disturbed & 2.5 & $0.5(0.86)$ \\
Social disability & - & $0.5(0.93)$ \\
Avoided going out & 0.0 & $0.2(0.40)$ \\
Problems in carrying out daily activities & 1.7 & $0.3(0.68)$ \\
Handicap & - & $0.8(1.19)$ \\
Had to spend a lot of money & 0.8 & $0.3(0.62)$ \\
Felt less confident & 4.1 & $0.6(0.89)$ \\
\hline
\end{tabular}

Table 4 Association between oral symptoms and severity of oral impact (S-OHIP(M) score) in study participants

\begin{tabular}{|c|c|c|c|c|}
\hline Variable & Adj. $b$ & $95 \% \mathrm{Cl}$ & t-statistic & $P$ value \\
\hline $\begin{array}{l}\text { Personal monthly } \\
\text { income (MYR) }\end{array}$ & -0.001 & $-0.003,0.000$ & -2.08 & 0.040 \\
\hline \multicolumn{5}{|l|}{ Toothache } \\
\hline \multicolumn{5}{|l|}{$\mathrm{No}^{\mathrm{a}}$} \\
\hline Yes & 4.31 & $1.65,6.97$ & 3.21 & 0.040 \\
\hline \multicolumn{5}{|l|}{ Cavitated tooth } \\
\hline \multicolumn{5}{|l|}{$\mathrm{No}^{\mathrm{a}}$} \\
\hline Yes & 3.44 & $1.12,5.76$ & 2.94 & 0.002 \\
\hline \multicolumn{5}{|l|}{ Gingival abscess } \\
\hline \multicolumn{5}{|l|}{$\mathrm{No}^{\mathrm{a}}$} \\
\hline Yes & 10.66 & $5.06,16.27$ & 3.77 & 0.004 \\
\hline \multicolumn{5}{|l|}{ Bad breath } \\
\hline \multicolumn{5}{|l|}{$\mathrm{No}^{\mathrm{a}}$} \\
\hline Yes & 7.59 & $4.44,10.74$ & 4.77 & $<0.001$ \\
\hline
\end{tabular}

Adj. $b=$ Adjusted regression coefficient

$R^{2}=0.431$; the model fits reasonably well; model assumptions were met; there was no interaction between independent variables, and no multicollinearity was detected ${ }^{a}$ Reference category 
Table 5 Mean S-OHIP(M) scores of participants with different general health perceptions

\begin{tabular}{llll}
\hline Variable & $\begin{array}{l}\text { Mean S-OHIP } \\
\text { (M) score (SD) }\end{array}$ & F-statistic (d.f.) & $P$ value \\
\hline General health perception & & & \\
Much/somewhat worse & $14.18(10.08)$ & $3.23(2,118)$ & 0.043 \\
About the same & $7.38(7.43)$ & & \\
Much/somewhat better & $8.58(7.58)$ & & \\
\hline
\end{tabular}

results were similar when we compared the 98 participants on HAART with the general population.

Multivariable analysis of the association between OHRQOL and HRQOL scores shows that participants with lower S-OHIP(M) scores have significantly higher scores in all SF-36 domains (Table 7). There were also several other significant determinants. In particular, sex was significant in the vitality domain, marital status in the physical functioning and role-emotional domains, employment status in the vitality and mental health domains, HAART status in the bodily pain domain, duration of HAART in the vitality and mental health domains, CD4+ T-lymphocyte count in the physical functioning, role-physical, bodily pain, general health,

Table 6 Comparison of mean SF-36 domain scores in study participants and the general population of Malaysia

\begin{tabular}{llll}
\hline SF-36 domain & Mean score $(\mathrm{SD})^{\mathrm{a}}$ & $\begin{array}{l}95 \% \mathrm{Cl} \text { of the } \\
\text { difference }\end{array}$ & $\begin{array}{l}P \text { value } \\
\text { All participants }(n=121)\end{array}$ \\
$\begin{array}{l}\text { Physical functioning } \\
\text { Role-physical }\end{array}$ & $80.79(20.97)$ & $-8.79,-1.42$ & 0.007 \\
Bodily pain & $77.50(23.11)$ & $3.38,11.70$ & $<0.001$ \\
General health & $59.88(21.37)$ & $-10.71,-3.02$ & 0.001 \\
Vitality & $67.89(20.76)$ & $-2.63,4.84$ & 0.560 \\
Role-emotional & $74.10(41.61)$ & $-12.61,2.36$ & 0.178 \\
Social functioning & $79.86(20.56)$ & $-7.58,-0.17$ & 0.040 \\
Mental health & $70.15(18.04)$ & $-7.76,-1.26$ & 0.007 \\
Participants on HAART $(n=98)$ & & \\
Physical functioning & $80.51(21.00)$ & $-9.68,-1.26$ & 0.011 \\
Role-physical & $68.11(39.12)$ & $-21.76,-6.07$ & 0.001 \\
Bodily pain & $76.64(23.48)$ & $1.98,11.39$ & 0.006 \\
General health & $61.58(21.09)$ & $-9.39,-0.93$ & 0.017 \\
Vitality & $67.40(20.91)$ & $-3.58,4.80$ & 0.774 \\
Role-emotional & $73.81(41.52)$ & $-13.74,2.90$ & 0.199 \\
Social functioning & $79.08(20.29)$ & $-8.72,-0.58$ & 0.026 \\
Mental health & $70.98(18.26)$ & $-7.34,-0.02$ & 0.049 \\
\hline
\end{tabular}

${ }^{a}$ Mean domain scores were compared with the following mean domain scores from a sample of the general population of Malaysia [30]: physical functioning, 85.98 (SD = 17.91); role-physical, $82.03(\mathrm{SD}=32.12$ ); bodily pain, $69.96(\mathrm{SD}=17.59)$; general health, $66.74(\mathrm{SD}=19.99)$; vitality, $66.79(\mathrm{SD}=17.68)$; role-emotional, 79.23 $(S D=35.92)$; social functioning, $83.73(S D=19.28)$; mental health, $74.66(S D=17.19)$ role-emotional and mental health domains, hepatitis $\mathrm{C}$ status in the physical functioning, role-emotional, and social functioning domains, tuberculosis in the rolephysical and vitality domains, gum swelling in the roleemotional domain, and general health perceptions in the physical functioning, role-physical, bodily pain, general health, and vitality domains.

The adjusted regression coefficient of each model (which explains the variation of the domain score) was as follows: physical functioning, $R^{2}=0.290$; role-physical, $R^{2}=0.465$; bodily pain, $R^{2}=0.323$; general health, $R^{2}=0.309$; vitality, $R^{2}=0.381$; role-emotional, $R^{2}=0.307$; social functioning, $R^{2}=0.153$; and mental health, $R^{2}=0.264$. All model assumptions were met, there was no interaction between independent variables, and there was no evidence of multicollinearity.

\section{Discussion}

The prevalence of oral impacts among PLWHA in this study is comparable with that reported for PLWHA receiving medical care in Brazil (34.0\%) [31] and HIVinfected individuals receiving care at the Special Need Unit of Adelaide Dental Hospital in Australia (33.3\%) [32]. However, the mean severity score of our participants was lower than in these previous studies. The prevalence and severity of oral impacts in the current study were considerably higher than those in the general adult population of Malaysia, reported as $29.3 \%$ and $5.87 \%$, respectively [33]. These findings show that the impact of oral diseases is greater for PLWHA than for the general population. The greatest impacts were discomfort due to food getting stuck and difficulty in chewing food. These findings are in accordance with the high number of participants who reported having oral symptoms related to the impacts, namely a cavitated tooth, toothache, and a loose tooth.

About three-quarters of the participants in this study reported having at least one oral symptom, yet most participants perceived their current oral health status as good or very good. Previous studies of different populations in Malaysia reported similar findings. In particular, a sample of antenatal mothers at a teaching hospital in the east coast of Peninsular Malaysia showed that most mothers reported their oral health status as good or very good, although most said they had at least one oral health problem [34]. Another study reported that about half of Malaysian adults (52.4\%) perceived their oral health as reasonably good, and $70 \%$ were satisfied with their oral health, although almost all of them (98.3\%) needed some form of dental treatment [33]. These discrepancies between self-perceived needs and normative needs underline the importance of oral health education to increase oral health awareness in the general public and at-risk groups, such as PLWHA. Our participants 
Table 7 Association between S-OHIP(M) score and score in each SF-36 health domain in study participants

\begin{tabular}{|c|c|c|c|c|c|c|c|c|}
\hline \multirow[t]{2}{*}{ Variable } & \multicolumn{8}{|c|}{ Adjusted regression coefficient } \\
\hline & $\mathrm{PF}$ & $\mathrm{RP}$ & $\mathrm{BP}$ & $\mathrm{GH}$ & VT & RE & SF & $\mathrm{MH}$ \\
\hline \multicolumn{9}{|l|}{ Sex } \\
\hline \multicolumn{9}{|l|}{ Female* } \\
\hline Male & - & - & - & - & $-8.45^{c}$ & - & - & - \\
\hline \multicolumn{9}{|l|}{ Marital status } \\
\hline \multicolumn{9}{|l|}{ Never married* } \\
\hline Married & $-11.96^{\mathrm{b}}$ & - & - & - & - & $20.00^{c}$ & - & - \\
\hline Divorced/widowed & $-9.52^{c}$ & - & - & - & - & 12.09 & - & - \\
\hline \multicolumn{9}{|l|}{ Employment status } \\
\hline \multicolumn{9}{|l|}{ Regular jobs* } \\
\hline Odd jobs & - & - & - & - & -2.84 & - & - & 0.85 \\
\hline Unemployed & - & - & - & - & $-9.18^{c}$ & - & - & $-7.48^{\mathrm{c}}$ \\
\hline \multicolumn{9}{|l|}{ HAART status } \\
\hline \multicolumn{9}{|l|}{$\mathrm{No}^{*}$} \\
\hline Yes & - & - & $10.32^{c}$ & - & - & - & - & - \\
\hline Duration of HAART (years) & - & - & - & - & $-1.06^{b}$ & - & - & $-0.61^{c}$ \\
\hline \multicolumn{9}{|l|}{ CD4+ count (cells/mm³) } \\
\hline \multicolumn{9}{|l|}{$<200^{*}$} \\
\hline $200-499$ & $11.82^{c}$ & $21.21^{\mathrm{c}}$ & $9.51^{\mathrm{c}}$ & 7.66 & - & $22.39^{c}$ & - & $8.93^{c}$ \\
\hline$\geq 500$ & $17.39^{\mathrm{b}}$ & $34.19^{\mathrm{a}}$ & $15.21^{b}$ & $16.63^{b}$ & - & $32.70^{b}$ & - & $15.18^{b}$ \\
\hline \multicolumn{9}{|l|}{ Hepatitis C } \\
\hline \multicolumn{9}{|l|}{$\mathrm{No}^{*}$} \\
\hline Yes & $-14.23^{b}$ & - & - & - & - & $-18.19^{c}$ & $-9.71^{c}$ & - \\
\hline \multicolumn{9}{|l|}{ Tuberculosis } \\
\hline \multicolumn{9}{|l|}{$\mathrm{No}^{*}$} \\
\hline Yes & - & $-28.20^{b}$ & - & - & $-14.72^{b}$ & - & - & - \\
\hline \multicolumn{9}{|l|}{ Gum swelling } \\
\hline \multicolumn{9}{|l|}{$\mathrm{No}^{*}$} \\
\hline Yes & - & - & - & - & - & $-18.22^{c}$ & - & - \\
\hline S-OHIP(M) score & $-0.58^{b}$ & $-1.85^{\mathrm{a}}$ & $-1.32^{\mathrm{a}}$ & $-0.99^{\mathrm{a}}$ & $-1.02^{\mathrm{a}}$ & $-1.35^{b}$ & $-0.69^{b}$ & $-0.81^{\mathrm{a}}$ \\
\hline \multicolumn{9}{|l|}{ General health perceptions } \\
\hline \multicolumn{9}{|l|}{ Much/somewhat worse* } \\
\hline About the same & $12.73^{c}$ & $30.73^{b}$ & $15.24^{c}$ & $14.88^{c}$ & 10.47 & - & - & - \\
\hline Much/somewhat better & $12.65^{c}$ & $33.48^{b}$ & $18.46^{\mathrm{b}}$ & $21.29^{\mathrm{a}}$ & $13.33^{c}$ & - & - & - \\
\hline
\end{tabular}

Abbreviations: PF physical functioning; RP role-physical; $B P$ bodily pain; $G H$ general health; $V T$ vitality; $R E$ role-emotional; $S F$ social functioning; $M H$ mental health *Reference category

${ }^{\mathrm{a}} P<0.001$

${ }^{\mathrm{b}} \mathrm{P}<0.01$

${ }^{c} P<0.05$

also perceived significant oral symptoms, possibly indicating unmet oral health needs among PLWHA in Malaysia. Additional studies also reported self-perceived unmet oral health needs among HIV-positive patients in other populations and countries $[35,36]$

According to Sischo and Broder [37], OHRQOL is "a function of various symptoms and experiences and represents the person's subjective perspective". In agreement with the original Wilson and Cleary model [11] and the version revised by Ferrans et al. [12], each of which highlighted symptoms as important determinants of functional status, our study showed that participants with oral symptoms (toothache, cavitated tooth, gum abscess, or bad breath) have more severe oral impact. 
Hence, these individuals had poorer OHRQOL than those without symptoms. These findings are in agreement with previous studies that also showed an association between oral symptoms and OHRQOL [38].

We also found that participants with lower personal income had significantly higher S-OHIP(M) scores, indicating more severe oral impact, in agreement with a study of OHRQOL among PLWHA in Sydney, Australia [39]. Besides income, other studies reported that individual characteristics, such as sex and ethnicity, were significantly associated with the OHRQOL of PLWHA [40]. However, we found no apparent influence of other individual characteristics on the OHRQOL of PLWHA.

Ferrans et al. [12] described environmental characteristics as social and physical environment that can influence health outcomes. In the present study, HAART status and HAART duration represent the environmental characteristics of the participants. HAART, which is currently the most effective treatment for HIV, suppresses viral replication and reduces plasma HIV viral load to below the detection limit, thereby allowing recovery of $\mathrm{CD} 4+\mathrm{T}$ lymphocytes and other immunologic functions [41]. HAART was first available in Malaysia in 1996, and starting in 2006, provision of free first-line antiretroviral therapy to all eligible PLWHA has become an important policy of the Ministry of Health as a national response to the HIV epidemic [7]. The introduction of HAART has led to a substantial decline in AIDS-related mortality and morbidity [5, 42-44], including the prevalence of HIV-related oral lesions [45]. However, we found no significant association between HAART and the severity of oral impact among our study participants. This is probably because other oral health problems (such as dental caries), not HIV-related oral lesions, were the main oral health problem among our participants. This is consistent with our finding that a cavitated tooth and toothache were the most common symptoms reported by our study participants, and these were significantly associated with reduced OHRQOL.

Most of our participants were on HAART, had a CD4 + T-lymphocyte count of at least 200 cells $/ \mathrm{mm}^{3}$, and were under 50 years of age. Hence, it might be expected that their HRQOL would be comparable to that of the general population. However, our results showed that the HRQOL of PLWHA was generally lower than that of the general Malaysian population [30]. Relative to the general population, our participants, including those who were on HAART, had more physical pain and disability, and poorer physical, mental, and social health functioning. These findings clearly indicate that PLWHA have a worse HRQOL. In agreement, a study of more than 3000 PLWHA in the United Kingdom showed that they had a significantly worse HRQOL than the general population, even though most of them had a stable immunologic and virologic status [46]. A study of 521
PLWHA enrolled in the Dublin HIV Cohort study found that the overall HRQOL of the participants was generally comparable with the general Irish population, although their scores in a few HRQOL dimensions were significantly lower [13]. The United States HIV Cost and Services Utilization Study also showed that the HRQOL of symptomatic PLWHA was worse than patients with other chronic diseases [47].

There is limited evidence, particularly from prospective studies, about the benefits of HAART on HRQOL. Some studies showed significant overall improvement under HAART $[48,49]$, some showed only modest improvement $[50,51]$, and others raised concerns about deterioration of physical health after long-term HAART [52]. A large multicentre prospective cohort study in the United States demonstrated that HAART was associated with significant short-term improvements in HRQOL, but continued use of HAART did not lead to further changes, in that HRQOL remained declined slightly at a subsequent follow-up [53]. We found that the duration of HAART was positively associated with decreased vitality and mental health scores. The inconsistent findings regarding the effects of HAART on HRQOL may be due to the effect of uncontrolled factors that impact the health and well-being of PLWHA, such as adverse drug reactions $[54,55]$ and other environmental determinants, such as social stigmatisation and discrimination [56]. Further research is necessary to fully understand the influence of these determinants on the HRQOL of PLWHA.

In this study, we used the SF-36 item that asks about the self-perceived change in health over time as an indicator of the general health perceptions of our participants. This is in accordance with the suggestion by Ferrans et al. [12] that this component is more appropriately measured using a single global question that asks people to rate their general health, instead of using outcome measures that are directed towards one specific dimension of health, such as functioning or symptoms. Clinical research commonly uses global rating of change scales to quantify a patient's change in health status over time due to an intervention or to follow the clinical course of a condition [57]. Although the outcome may be influenced by various health dimensions, use of a single global question allows the patient to consider the aspects of health that are relevant to him or her, and to give an overall evaluation on a scale ranging from poor to excellent [12]. Some of our participants thought they were much worse or somewhat worse at the time of the survey relative to the previous year, and these participants had significantly higher S-OHIP (M) scores than those who thought they were about the same. These findings provide evidence of an important link between oral health and general health. 
Many studies have assessed the determinants of HRQOL in PLWHA, but only few have reported the relationship between OHRQOL and HRQOL. In the present study, we found a significantly positive association between OHRQOL and all HRQOL dimensions measured by the Malay version of the SF-36. These findings are in agreement with a previous study of PLWHA in Minas Gerais, Brazil, which also showed a positive association between OHRQOL and HRQOL [31]. Our study also demonstrated the linkages among HRQOL elements (biological function, symptoms, functional status, and general health self-perceptions) and determinants (individual characteristics and environmental characteristics). This supports application of the revised Wilson and Cleary model by Ferrans et al. [12] for PLWHA.

Most HRQOL instruments used in studies of PLWHA, either generic or HIV-specific, do not have items that adequately assess oral symptoms or oral impacts. Hence, most of the literature that used HRQOL instruments to identify the factors associated with HRQOL among PLWHA failed to capture the influence of oral health [58], although many studies have demonstrated this association in HIV-infected individuals and in other groups of patients and populations [31, 38, 59-61]. Oral health is an important determinant of HRQOL, and should therefore be an integral part of the HRQOL construct used in studies of PLWHA. An OHRQOL instrument, such as OHIP or the Oral Impact of Daily Performance (OIDP), should be used as an adjunct to the currently available HRQOL instruments in future studies.

This study has several limitations. First, all of our participants attended follow-up care at the hospital, and were therefore mostly in relatively good physical condition. Thus, our results cannot be applied to all PLWHA, such as those who are inpatients, those at home and unable to come to the clinic, and those not receiving medical care. Second, the results from a self-administered questionnaire to collect information about oral symptoms must be interpreted with caution, because we used a close-ended response format that lists all possible oral symptoms. Although we included one open-ended question to allow participants to state symptoms other than those listed, none of the participants used this option, so it is possible that we might have missed certain symptoms. Despite this limitation, the use of a self-administered questionnaire provides greater anonymity for study participants. A selfadministered questionnaire also allows the participants to take their time in answering questions, without being led by an interviewer.

\section{Conclusions}

Oral health problems are common among PLWHA who receive medical care at the Infectious Disease Clinic, HRPZ II, in Kota Bharu (Kelantan, Malaysia). This finding highlights the importance of collaboration between medical and dental professionals to improve the delivery of oral health care services to PLWHA. Our study also provides evidence for important links among oral symptoms, OHRQOL, and HRQOL in PLWHA. This indicates that measures of oral symptoms and oral impacts should also be used in measuring the HRQOL of PLWHA.

\section{Additional file}

Additional file 1: Structured questionnaire. (PDF 77 kb)

\section{Abbreviations}

CD4: cluster of differentiation 4; HAART: highly active antiretroviral therapy; HIV: human immunodeficiency virus; HRQOL: health-related quality of life; MYR: Malaysian Ringgit; OHRQOL: oral health-related quality of life; PLWHA: people living with HIV/AIDS; SD: standard deviation; SF-36: 36item Medical Outcome Study Short Form; S-OHIP(M): the Malay version of short Oral Health Impact Profile; VIF: variance inflation factor

\section{Acknowledgements}

The authors would like to thank the Director of Health Malaysia for permission to conduct this study at the Ministry of Health premises and to publish this paper. We also would like to express our highest gratitude to the staff of the Infectious Disease Clinic, Hospital Raja Perempuan Zainab II, Kota Bharu Kelantan

\section{Funding}

This study did not receive any specific grant from funding agencies in the public, commercial, or not-for-profit sectors.

\section{Availability of data and materials}

Data generated and analysed during the current study are not publicly available due to confidentiality agreement with the participants.

\section{Authors' contributions}

NM, NS, AY, and AMJ contributed to the conception and design of the study. NM and AMJ contributed to data acquisition. NM and NS contributed to data management and analyses. NM, NS, AY, and AMJ contributed to data interpretation. NS and NM contributed to preparation of the manuscript. NM, NS, AY, and AMJ critically reviewed the manuscript. NM, NS, AY, and AMJ revised and approved the final manuscript.

\section{Ethics approval and consent to participate}

This study was approved by the Universiti Sains Malaysia Human Research and Ethics Committee (Ref: USM/JEPeM/15010121) and the Ministry of Health Malaysia Medical Research and Ethics Committee (Ref: (11) KKM/NIHSEC/P15-484). This study was registered with the National Medical Research Register of Malaysia (NMRR ID: NMRR-15-362-24,805 (IIR)). Written informed consent was obtained from all individual participants included in the study.

Consent for publication

Not applicable.

\section{Competing interests}

The authors declare that they have no competing interests.

\section{Publisher's Note}

Springer Nature remains neutral with regard to jurisdictional claims in published maps and institutional affiliations.

\section{Author details}

${ }^{1}$ School of Dental Sciences, Universiti Sains Malaysia, Health Campus, 16150 Kubang Kerian, Kelantan, Malaysia. ${ }^{2}$ Department of Medicine, Hospital Raja Perempuan Zainab II, 15586 Kota Bharu, Kelantan, Malaysia. 


\section{Received: 16 September 2016 Accepted: 8 August 2017}

\section{Published online: 22 August 2017}

\section{References}

1. UNAIDS. Global AIDS Update 2016. Geneva: UNAIDS; 2016.

2. Ledergerber B, Egger M, Erard V, Weber R, Hirschel B, Furrer H, Battegay M, Vernazza P, Bernasconi E, Opravil M, et al. AIDS-related opportunistic illnesses occurring after initiation of potent antiretroviral therapy: the Swiss HIV cohort study. JAMA. 1999;282(23):2220-6.

3. Loutfy MR, Wu W, Letchumanan M, Bondy L, Antoniou T, Margolese S, Zhang Y, Rueda S, McGee F, Peck R, et al. Systematic review of HIV transmission between heterosexual serodiscordant couples where the HIV-positive partner is fully suppressed on antiretroviral therapy. PLoS One. 2013;8(2):e55747.

4. d'Arminio Monforte A, Sabin CA, Phillips A, Sterne J, May M, Justice A, Dabis F, Grabar S, Ledergerber B, Gill J, et al. The changing incidence of AIDS events in patients receiving highly active antiretroviral therapy. Arch Intern Med. 2005;165(4):416-23.

5. Kaplan JE, Hanson D, Dworkin MS, Frederick T, Bertolli J, Lindegren ML, Holmberg $\mathrm{S}$, Jones JL. Epidemiology of human immunodeficiency virusassociated opportunistic infections in the United States in the era of highly active antiretroviral therapy. Clin Infect Dis. 2000;30(Suppl 1):S5-14.

6. UNAIDS. AIDS by the numbers 2015. Geneva: UNAIDS; 2015

7. Ministry of Health Malaysia. Global AIDS response progress. Report Malaysia 2015. Kuala Lumpur: Ministry of Health Malaysia; 2015.

8. Grossman HA, Sullivan PS, Wu AW. Quality of life and HIV: current assessment tools and future directions for clinical practice. AIDS Read. 2003;12:583-97.

9. Fayers PM, Machin D. Quality of life. The assessment, analysis and interpretation of patient-reported outcomes. 2nd edition. West Sussex: John Wiley \& Sons Ltd; 2007.

10. Bakas T, McLennon SM, Carpenter JS, Buelow JM, Otte JL, Hanna KM, Ellett ML, Hadler KA, Welch JL: Systematic review of health-related quality of life models. Health Qual Life Outcomes 2012, Nov 16;10:134. doi: 10.1186/1477-7525-10-134

11. Wilson IB, Cleary PD. Linking clinical variables with health-related quality of life: a conceptual model of patient outcomes. JAMA. 1995;273(1):59-65.

12. Ferrans CE, Zerwic JJ, Wilbur JE, Larson JL. Conceptual model of healthrelated quality of life. J Nurs Scholarsh. 2005;37(4):336-42.

13. George S, Bergin C, Clarke S, Courtney G, Codd MB. Health-related quality of life and associated factors in people with HIV: an Irish cohort study. Health Qual Life Outcomes. 2016;14(1):115. doi:10.1186/s12955-016-0517-4.

14. Hasanah C, Zaliha A, Mahiran M. Factors influencing the quality of life in patients with HIV in Malaysia. Qual Life Res. 2011;20(1):91-100.

15. Rueda S, Raboud J, Mustard C, Bayoumi A, Lavis JN, Rourke SB. Employment status is associated with both physical and mental health quality of life in people living with HIV. AIDS Care. 2011;23(4):435-43.

16. Nojomi M, Anbary K, Ranjbar M. Health-related quality of life in patients with HIV/AIDS. Arch Iranian Med. 2008;11(6):608-12.

17. Nglazi MD, West SJ, Dave JA, Levitt NS, Lambert EV. Quality of life in individuals living with HIV/AIDS attending a public sector antiretroviral service in cape town, South Africa. BMC Public Health. 2014;14:676. doi:10.1186/1471-2458-14-676.

18. Murri R, Fantoni M, Del Borgo C, Visona R, Barracco A, Zambelli A, Testa L, Orchi N, Tozzi V, Bosco O, et al. Determinants of health-related quality of life in HIV-infected patients. AIDS Care. 2003;15(4):581-90.

19. Clayson DJ, Wild DJ, Quarterman P, Duprat-Lomon I, Kubin M, Coons SJ. A comparative review of health-related quality-of-life measures for use in HIV/ AIDS clinical trials. PharmacoEconomics. 2006:24(8):751-65.

20. Greenspan JS, Greenspan D. The epidemiology of the oral lesions of HIV infection in the developed world. Oral Dis. 2002:8:34-9.

21. Bhayat A, Yengopal V, Rudolph M. Predictive value of group I oral lesions for HIV infection. Oral Surg Oral Med Oral Pathol Oral Radiol Endod. 2010;109(5):720-3.

22. Aleixo RQ, Scherma AP, Guimarães G, Cortelli JR, Cortelli SC. DMFT index and oral mucosal lesions associated with HIV infection: cross-sectional study in Porto Velho, Amazonian region - Brazil. Braz J Infect Dis. 2010;14(5):449-56.

23. Santo AE, Tagliaferro EP, Ambrosano GM, Meneghim MC, Pereira AC. Dental status of Portuguese HIV+ patients and related variables: a multivariate analysis. Oral Dis. 2010;16(2):176-84

24. Robinson PG, Sheiham A, Challacombe SJ, Zakrzewska JM. The periodontal health of homosexual men with HIV infection: a controlled study. Oral Dis. 1996;2(1):45-52.

25. Slade GD, Spencer AJ. Development and evaluation of the oral health impact profile. Community Dent Health. 1994;11(1):3-11.
26. Locker D. Measuring oral health: a conceptual framework. Community Dent Health. 1988;5(1):3-18.

27. Saub R, Locker D, Allison P. Derivation and validation of the short version of the Malaysian oral health impact profile. Community Dent Oral Epidemiol. 2005;33(5):378-83.

28. Sararaks S, Azman AB, Low LL, Rugayah B, Aziah AM, Hooi LN, Abdul Razak M, Norhaya MR, Lim KB, Azian AA, et al. Validity and reliability of the SF-36: the Malaysian context. Med J Malaysia. 2005;60(2):163-79.

29. Ware JE, Snow KK, Kosinski M, Gandek B. SF-36 health survey: manual and interpretation guide. Boston: The Health Institute, New England Medical Center; 1993.

30. Azman AB, Sararaks S, Rugayah B, Low LL, Azian AA, Geeta S, Tiew CT. Quality of life of the Malaysian general population: results from a postal survey using the SF-36. Med J Malaysia. 2003;58(5):694-711.

31. de Quadros Coelho M, Cordeiro JM, Vargas AMD, de Barros Lima AME, Santa Rosa TTDA, Senna MIB, Ferreira RC. Functional and psychosocial impact of oral disorders and quality of life of people living with HIV/AIDS. Qual Life Res. 2015;24(2):503-11.

32. Liberali SA, Coates EA, Freeman AD, Logan RM, Jamieson L, Mejia G. Oral conditions and their social impact among HIV dental patients, 18 years on. Aust Dent J. 2013:58(1):18-25.

33. Ministry of Health Malaysia. National Oral Health Survey of adults 2010. Kuala Lumpur: Oral Health Division, Ministry of Health Malaysia; 2013.

34. Saddki N, Yusoff A, Hwang YL. Factors associated with dental visit and barriers to utilisation of oral health care services in a sample of antenatal mothers in Hospital Universiti Sains Malaysia. BMC Public Health. 2010;10(1):75.

35. Patton LL, Strauss RP, McKaig RG, Porter DR, Eron JJ. Perceived oral health status, unmet needs, and barriers to dental care among HIV/AIDS patients in a North Carolina cohort: impacts of race. J Public Health Dent. 2003:63(2):86-91.

36. Jeanty Y, Cardenas G, Fox JE, Pereyra M, Diaz C, Bednarsh H, Reznik DA, Abel SN, Bachman SS, Metsch LR. Correlates of unmet dental care need among HIV-positive people since being diagnosed with HIV. Public Health Rep. 2012;127(Suppl 2):17-24.

37. Sischo L, Broder HL. Oral health-related quality of life: what, why, how, and future implications. J Dent Res. 2011:90(11):1264-70.

38. Coulter ID, Heslin KC, Marcus M, Hays RD, Freed J, Der-Martirosian C, Guzman-Becerra N, Cunningham WE, Andersen RM, Shapiro MF. Associations of self-reported oral health with physical and mental health in a nationally representative sample of HIV persons receiving medical care. Qual Life Res. 2002;11(1):57-70

39. Jeganathan S, Batterham M, Begley K, Purnomo J, Houtzager L. Predictors of oral health quality of life in HIV-1 infected patients attending routine care in Australia. J Public Health Dent. 2011;71(3):248-51.

40. Tomar SL, Pereyra M, Metsch LR. Oral health-related quality of life among low-income adults living with HIV. J Public Health Dent. 2011;71(3):241-7.

41. Arts EJ, Hazuda DJ. HIV-1 antiretroviral drug therapy. Cold Spring Harb Perspect Med. 2012;2(4):a007161. doi:10.1101/cshperspect.a007161.

42. Palella FJ Jr, Baker RK, Moorman AC, Chmiel JS, Wood KC, Brooks JT, Holmberg SD, HIV Outpatient Study Investigators. Mortality in the highly active antiretroviral therapy era: changing causes of death and disease in the HIV outpatient study. J Acquir Immune Defic Syndr. 2006;43(1):27-34.

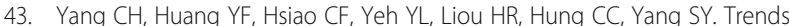
of mortality and causes of death among HIV-infected patients in Taiwan, 1984-2005. HIV Med. 2008:9(7):535-43.

44. Fairall LR, Bachmann MO, Louwagie GM, van Vuuren C, Chikobvu P, Steyn D, Staniland GH, Timmerman V, Msimanga M, Seebregts CJ, et al. Effectiveness of antiretroviral treatment in a south African program: a cohort study. Arch Intern Med. 2008;168(1):86-93.

45. Ramírez-Amador V, Esquivel-Pedraza L, Sierra-Madero J, Anaya-Saavedra G, González-Ramírez I, Ponce-de-León S. The changing clinical spectrum of human immunodeficiency virus (HIV)-related oral lesions in 1,000 consecutive patients: a 12-year study in a referral center in Mexico. Medicine (Baltimore). 2003:82(1):39-50.

46. Miners A, Phillips A, Kreif N, Rodger A, Speakman A, Fisher M, Anderson J, Collins S, Hart G, Sherr L, et al. Health-related quality-of-life of people with HIV in the era of combination antiretroviral treatment: a cross-sectional comparison with the general population. Lancet HIV. 2014:1(1):e32-40.

47. Hays RD, Cunningham WE, Sherbourne CD, Wilson IB, Wu AW, Cleary PD, McCaffrey DF, Fleishman JA, Crystal S, Collins R, et al. Health-related quality of life in patients with human immunodeficiency virus infection in the 
United States: results from the HIV cost and services utilization study. Am J Med. 2000;108(9):714-22.

48. Jelsma J, Maclean E, Hughes J, Tinise X, Darder M. An investigation into the health-related quality of life of individuals living with HIV who are receiving HAART. AIDS Care. 2005;17(5):579-88.

49. Tomita A, Garrett N, Werner L, Burns JK, Ngcobo N, Zuma N, Mlisana K, van Loggerenberg F, Abdool Karim SS. Impact of antiretroviral therapy on healthrelated quality of life among south African women in the CAPRISA 002 acute infection study. AIDS Behav. 2014;18(9):1801-7.

50. Saunders DS, Burgoyne RW. Evaluating health-related wellbeing outcomes among outpatient adults with human immunodeficiency virus infection in the HAART era. Int J STD AIDS. 2002;13(10):683-90.

51. Casado A, Badia X, Consiglio E, Ferrer E, González A, Pedrol E, Gatell JM, Azuaje C, Llibre JM, Aranda M, et al. Health-related quality of life in HIVinfected naive patients treated with nelfinavir or nevirapine associated with ZDV/3TC (the COMBINE-QoL substudy). HIV Clin Trials. 2004;5(3):132-9.

52. Liu C, Ostrow D, Detels R, Hu Z, Johnson L, Kingsley L, Jacobson LP. Impacts of HIV infection and HAART use on quality of life. Qual Life Res. 2006;15(6):941-9.

53. Liu C, Weber K, Robison E, Hu Z, Jacobson LP, Gange SJ. Assessing the effect of HAART on change in quality of life among HIV-infected women. AIDS Res Ther. 2006:3:6. doi:10.1186/1742-6405-3-6.

54. Tran BX. Quality of life outcomes of antiretroviral treatment for HIV/AIDS patients in Vietnam. PLoS One. 2012;7(7):e41062. doi:10.1371/journal. pone.0041062.

55. Jaquet A, Garanet F, Balestre E, Ekouevi DK, Azani J, Bognounou R, Dah E, Kondombo JC, Dabis F, Drabo J. Antiretroviral treatment and quality of life in Africans living with HIV: 12-month follow-up in Burkina Faso. J Int AIDS Soc. 2013;16:18867. doi:10.7448/IAS.16.1.18867.

56. Chambers LA, Rueda S, Baker DN, Wilson MG, Deutsch R, Raeifar E, Rourke SB, Stigma Review Team. Stigma, HIV and health: a qualitative synthesis. BMC Public Health. 2015;15:848. doi:10.1186/s12889-015-2197-0.

57. Kamper SJ, Maher CG, Mackay G. Global rating of change scales: a review of strengths and weaknesses and considerations for design. J Man Manip Ther. 2009;17(3):163-70

58. Degroote S, Vogelaers D, Vandijck DM. What determines health-related quality of life among people living with HIV: an updated review of the literature. Arch Public Health. 2014;72(1):40.

59. Shimada A, Sasaki Y, Mataki S. An evaluation of self-reported oral health and health-related quality of life. J Med Dent Sci. 2005;52(1):65-72.

60. Reissmann DR, John MT, Schierz O, Kriston L, Hinz A. Association between perceived oral and general health. J Dent. 2013;41(7):581-9.

61. Zimmer S, Bergmann N, Gabrun E, Barthel C, Raab W, Rüffer J-U. Association between oral health-related and general health-related quality of life in subjects attending dental offices in Germany. J Public Health Dent. 2010;70(2):167-70.

\section{Submit your next manuscript to BioMed Central and we will help you at every step:}

- We accept pre-submission inquiries

- Our selector tool helps you to find the most relevant journal

- We provide round the clock customer support

- Convenient online submission

- Thorough peer review

- Inclusion in PubMed and all major indexing services

- Maximum visibility for your research

Submit your manuscript at www.biomedcentral.com/submit

CBiomed Central 